\title{
Associations between diabetic retinopathy and systemic risk factors
}

\author{
Noel Wat, Raymond LM Wong *, lan YH Wong
}

\section{A B S T R A C T}

Introduction: Diabetes mellitus is a systemic disease with complications that include sight-threatening diabetic retinopathy. It is essential to understand the risk factors of diabetic retinopathy before effective prevention can be implemented. The aim of this review was to examine the association between diabetic retinopathy and systemic risk factors.

Methods: A PubMed literature search was performed up to May 2016 to identify articles reporting associations between diabetic retinopathy and systemic risk factors; only publications written in English were included. Relevant articles were selected and analysed.

Results: Patients with diabetic retinopathy were more likely to have poor glycaemic control as reflected by a higher glycated haemoglobin, longer duration of diabetes, and use of insulin therapy for treatment. For other systemic risk factors, hypertension was positively associated with prevalence and progression of diabetic retinopathy. No clear association between

This article was published on 24 Oct 2016 at www.hkmj.org. obesity, hyperlipidaemia, gender, or smoking with diabetic retinopathy has been established as studies reported inconsistent findings. Myopia was a protective factor for the development of diabetic retinopathy. Several genetic polymorphisms were also found to be associated with an increased risk of development of diabetic retinopathy.

Conclusions: Good glycaemic and blood pressure control remain the most important modifiable risk factors to reduce the risk of progression of diabetic retinopathy and vision loss.

\section{Hong Kong Med J 2016;22:589-99}

DOI: $10.12809 / \mathrm{hkmj} 164869$

${ }^{1} \mathrm{~N}$ Wat, MB, ChB, BSc

1,2 RLM Wong *, MB, BS, MRCSEd(Ophth)

${ }^{3}$ IYH Wong, MB, BS, FRCOphth

Department of Ophthalmology and Visual Sciences, The Chinese University of Hong Kong, Shatin, Hong Kong

2 Hong Kong Eye Hospital, Argyle Street, Hong Kong

Department of Ophthalmology, The University of Hong Kong, Pokfulam, Hong Kong

* Corresponding author: raymondwIm@hotmail.com

\section{Introduction}

Diabetic retinopathy is the leading cause of blindness in adults living in developed countries. ${ }^{1}$ Almost all patients with type 1 diabetes mellitus (DM) and more than $60 \%$ of patients with type 2 DM will develop some degree of retinopathy after a 20-year history of diabetes. ${ }^{2}$ It has also been well established that DM increases the risk of cardiovascular disease. ${ }^{3}$ Cheng et $\mathrm{al}^{4}$ found that the prevalence of diabetic retinopathy associated with one, two, three, or four cardiometabolic risk factors was 16.0\%, 17.6\%, 21.3\%, or $25.1 \%$, respectively $(\mathrm{P}=0.001)$. This implies a relationship between systemic health conditions and diabetic retinopathy. In order to help identify and to prevent progression of this ophthalmic complication of diabetes, a better understanding of its association with systemic risk factors is necessary.

\section{Methods}

A PubMed literature search was conducted up to May 2016 using the following key words: "diabetic retinopathy", "prevalence", “epidemiology", "systemic associations", "risk factors", "diabetic control", "HbA1c", "blood glucose", "hypertension", "hyperlipidaemia", "cholesterol", "obesity", "smoking", "myopia", and "genetics". Articles reporting systemic associations of diabetic retinopathy were selected and analysed. A search through the references of the retrieved articles was also performed. Only articles published in English were reviewed. During selection of the articles, prospective studies had a higher ranking than retrospective ones.

\section{Results}

\section{Prevalence of diabetic retinopathy in diabetic} patients

Approximately a quarter to one third of adults living with diabetes are reported to have diabetic retinopathy. In a recent systematic literature review, Yau et $\mathrm{al}^{5}$ estimated that the overall global prevalence of diabetic retinopathy was $34.6 \%$. The Multi-Ethnic Study of Atherosclerosis (MESA) reported a prevalence of $33.2 \%$ in adults within the US population. ${ }^{6}$ A more recent study of the US population reports a lower prevalence of diabetic retinopathy of $28.5 \% .^{7}$ 
糖尿病視網膜病變和系統性風險因素之間的關聯 屈匡祈、黃禮文、王逸軒

引言：糖尿病是一種全身性疾病, 引起的併發症如糖尿病視網膜病變 會對視力構成威脅。了解糖尿病視網膜病變的風險因素才可以預防此 病症。本文旨在研究糖尿病視網膜病變和系統性風險因素之間的關 聯。

方法：通過PubMed數據庫搜索直至2016年5月為止所有報導糖尿病 視網膜病變與系統性風險因素相關性的文章。本研究只選取英語文 章, 並分析相關研究結果。

結果：糖尿病視網膜病變患者普遍有較高糖化血紅蛋白水平、糖尿病 持續時間較長和使用胰島素作治療, 這些均反映其血糖控制不佳。至 於其他系統性風險因素, 高血壓與糖尿病視網膜病變的患病率和嚴重 程度呈正相關。由於研究結果並非一致, 肥胖、高脂血症、性別和吸 煙均與糖尿病視網膜病變沒有明顯關聯。近視是減低糖尿病視網膜病 變的一種保護因素。此外, 有幾個多態性基因與糖尿病視網膜病變的 風險增加有關。

結論：有效控制血糖和血壓可減低糖尿病視網膜病變的風險及避免喪 失視力。 comparable with their Caucasian counterparts. ${ }^{6}$

Differences in prevalence rates of diabetic retinopathy between populations may be due to both genetic factors and access to health care. Moreover, ethnicity is complex and multifactorial; alone it may not fully explain the differences in prevalence rates of diabetic retinopathy reported. Urbanisation and socio-economic status may also play a role in the prevalence of diabetic retinopathy. ${ }^{18}$ Additionally, discrepancies between studies of diabetic retinopathy prevalence may depend on several factors including study methodology. Some studies may have used different cut-off values for glycated haemoglobin (HbA1c), oral glucose tolerance test, and spot glucose to define a diagnosis of DM, thereby increasing the heterogeneity in the overall study population. The method of diabetic retinopathy screening and reporting logistics also varied among studies. For studies using retinal photographs as screening tools, the differences in the number of fundus photographs taken and whether pupil dilatation was performed before retinal assessment may have influenced the number of cases of diabetic retinopathy identified.

Within the Caucasian population in the US, the prevalence of diabetic retinopathy ranges from $24.8 \%$ to $26.4 \%{ }^{6,7}$ This is comparable with studies in western Europe with largely Caucasian populations, such as in the Gutenberg Health Study in Germany with a prevalence of $21.7 \%^{8}$ and Tromsø Eye Study in Norway with a prevalence of $26.8 \%{ }^{9}$

Multiple studies have reported a higher prevalence of diabetic retinopathy in black and Hispanic populations. Studies performed in the US reported a prevalence of $36.7 \%^{6}$ and $38.8 \%{ }^{7}$ in African American populations. Additionally, the Los Angeles Latino Eye Study (LALES) reported that $46 \%$ of Hispanic Americans with type 2 DM had diabetic retinopathy..$^{10}$ The MESA study ${ }^{6}$ and a more recent study by Zhang et $\mathrm{al}^{7}$ reported a lower prevalence of $37.4 \%$ and $34.0 \%$, respectively in the Hispanic American population.

There is considerable variation in prevalence rates of diabetic retinopathy within the Chinese population. The prevalence in Hong Kong has been reported between $28.4 \%$ and $39.2 \%$ in different studies. ${ }^{11-13} \mathrm{~A}$ more recent study by Lian et $\mathrm{al}^{14}$ on a local screening programme for diabetic retinopathy reported a prevalence rate of $39.0 \%$ (95\% confidence interval [CI], 38.8\%-39.2\%) in Hong Kong. Chen et $\mathrm{al}^{15}$ reported a prevalence of $35.0 \%$ in Taiwanese diabetic patients. Similarly, the comprehensive Beijing Eye Study covering both urban and rural Chinese populations reported a prevalence of $37 \%,{ }^{16}$ in comparison with the Handan Eye Study focusing on rural China that reported a higher prevalence of 43.1\%. ${ }^{17}$ The MESA study included data on Chinese Americans and reported a prevalence rate of $25.7 \%$,

\section{Classification of diabetic retinopathy}

The Early Treatment Diabetic Retinopathy Study (ETDRS) Diabetic Retinopathy Grading Scale (Modified Airlie House) and International Clinical two major and most commonly used classification systems for diabetic retinopathy. The ETDRS Grading Scale is more commonly used in research contexts whereas the ICDR Severity Scale is more commonly used in the clinical context. Additionally, the United Kingdom National Screening Committee (UK NSC) diabetic retinopathy grading system is notable for its widespread use in digital fundus photo screening

In general, diabetic retinopathy can be classified as non-proliferative or proliferative. Non-proliferative can then be further classified by severity ranging from mild to moderate and severe. Non-proliferative diabetic retinopathy (NPDR) is characterised by the presence of microaneurysms, hard exudates, cotton-wool spots, and/or retinal haemorrhages. Pre-proliferative diabetic retinopathy changes include vasculopathies such as intraretinal microvascular abnormality (IRMA) whereas proliferative diabetic retinopathy is defined by the presence of neovascularisation or vitreous haemorrhage or preretinal haemorrhage.

The ETDRS Diabetic Retinopathy Grading Scale assigns a retinopathy severity score from level 10 to 85. If no abnormality is found, ETDRS level 10 is assigned. If only microaneurysms are present, ETDRS level 20 (very mild NPDR) is assigned. The ETDRS level 35 is equivalent to mild NPDR, and is characterised by the presence Diabetic Retinopathy (ICDR) Severity Scale are the programmes worldwide. 
of hard exudates, cotton-wool spots, and/or mild retinal haemorrhages. Standard retinal photographs of retinal haemorrhages and IRMA are used to define moderate and severe NPDR in the ETDRS grading. The number of quadrants in which those signs are present is also taken into account. In contrast, a simple 4-2-1 rule is used in the ICDR Severity Scale: mild NPDR is defined as the presence of microaneurysms only. Severe NPDR is diagnosed when there are $\geq 20$ diffuse intraretinal haemorrhages and/or microaneurysms in all four quadrants, venous beading in at least two quadrants, or intraretinal microvascular abnormalities in at least one quadrant. Moderate NPDR on the other hand has severity falling below the 4-2-1 rule but more than merely microaneurysms. In both grading scales, proliferative diabetic retinopathy is defined as the presence of neovascularisation. High-risk and advanced proliferative diabetic retinopathy (ETDRS level, 71-85) refers to the presence of neovascularisation complications including preretinal haemorrhage, vitreous haemorrhage, or retinal detachment. ${ }^{19}$

Under the UK NSC diabetic retinopathy screening system, fundus photos are given a letter and numerical grading: $\mathrm{R} 0$ is assigned if no abnormality is found; $\mathrm{R} 1$ is given in early diabetic retinopathy with evidence of microaneurysms, retinal haemorrhage, or other features of diabetic retinopathy; R2 and R3 ratings are assigned in preproliferative and proliferative diabetic retinopathy, respectively. $\mathrm{M} 1$ is designated in cases with maculopathy, the presence of which is used to predict the presence of clinically significant macular oedema that requires treatment. P1 is assigned if the fundus photograph shows evidence of previous panretinal laser photocoagulation. Accordingly $\mathrm{MO}$ and $\mathrm{PO}$ are given respectively if the above characteristics are absent. Finally, a grading of $U$ is given if an image is regarded as ungradable, ${ }^{20}$ common reasons include dense cataract and corneal scars.

\section{Diabetes and diabetic retinopathy}

\section{Glycaemic control}

Glycated haemoglobin is a commonly used marker for monitoring glycaemic control. Multiple studies have consistently shown $\mathrm{HbA} 1 \mathrm{c}$ to be an independent risk factor for diabetic retinopathy. ${ }^{6,7,10,21,22} \mathrm{~A}$ higher $\mathrm{HbA1c}$ is associated with both increased incidence as well as progression of diabetic retinopathy. ${ }^{21}$ The LALES study found a $22 \%$ increase in prevalence of diabetic retinopathy with $1 \%$ increase in HbA1c. Data suggested a plateau of the curve at HbA1c of $\geq 11 \%$, however. ${ }^{10}$ Elevated HbA1c reflects poorly controlled diabetes, which is one of the major causes of complications in DM including diabetic retinopathy. Nonetheless, the United Kingdom Prospective Diabetes Study (UKPDS) demonstrated that even a good HbA1c level of $7.0 \%$ had an absolute risk of 7.9 per 1000 patient-years for retinal laser photocoagulation. ${ }^{10,23}$ This emphasises the importance of optimal glycaemic control in diabetic patients in order to prevent diabetic retinopathy. In contrast, this association was not seen in youngonset type $1 \mathrm{DM},{ }^{24}$ a difference that may be attributed to the role of hyperglycaemic memory. ${ }^{25}$

The ACCORD study ${ }^{26}$ compared the effects of intensive glycaemic treatment with target HbA1c of $<6.0 \%$ compared with standard treatment with target HbA1c of $7.0 \%$ to $7.9 \%$. The authors found a decreased rate of progression of diabetic retinopathy in the intensive treatment group, $7.3 \%$, versus $10.4 \%$ in the standard therapy group (adjusted odds ratio $[\mathrm{OR}]=0.67 ; 95 \% \mathrm{CI}, 0.51-0.87 ; \mathrm{P}=0.003) .{ }^{26}$ Despite the perceived benefit of reduced progression of diabetic retinopathy, intensive glycaemic control is not without risk. The ACCORD study found an increased risk of hypoglycaemia requiring medical assistance $(10.5 \%$ vs $3.5 \% ; \mathrm{P}=0.001)$, weight gain of $>10 \mathrm{~kg}(27.8 \%$ vs $14.1 \%$; $\mathrm{P}=0.001$ ), and all-cause mortality (hazard ratio $=1.22$; 95\% CI, 1.01-1.46; $\mathrm{P}=0.04){ }^{27}$ Similar findings have also been demonstrated in the Diabetes Control and Complications Trial (DCCT). ${ }^{28}$ The authors reported that intensive diabetes control therapy reduced the adjusted mean risk for development of retinopathy by $76 \%$, but at a cost of a $33 \%$ increased risk of weight gain and a 3-times higher risk of severe hypoglycaemia. ${ }^{28}$ Thus, one must balance the benefit of reducing the risk of diabetic retinopathy and the risk of tight glycaemic control when treating DM. As demonstrated in this review, however, multiple factors play a role in the development and progression of diabetic retinopathy, hence tight blood glucose control alone may not entirely prevent the development of diabetic retinopathy. Furthermore, Mohamed et $\mathrm{al}^{29}$ have recommended that in patients with diabetic retinopathy, a HbA1c level of 7\% is ideal in reducing progression of and new development of diabetic retinopathy.

Studies have also found a significantly higher fasting plasma glucose in subjects with diabetic retinopathy. ${ }^{6,16}$ Xie et $\mathrm{al}^{16}$ found that patients with diabetic retinopathy had a mean $( \pm$ standard deviation) fasting plasma glucose level of $8.88 \pm 4.56$ $\mathrm{mmol} / \mathrm{L}$ compared with $7.70 \pm 2.80 \mathrm{mmol} / \mathrm{L}$ in those without diabetic retinopathy. This association may also be due to the effects of hyperglycaemia causing retinopathy.

\section{Duration of diabetes}

An unmodifiable risk factor, prolonged duration of diabetes, has been consistently demonstrated to be a risk factor for diabetic retinopathy, ${ }^{6,8,16,21,24,30} \mathrm{In}$ fact, one study reported that patients with diabetic retinopathy had longer duration of diabetes, double than those without retinopathy $(25 \pm 10$ vs 
$12 \pm 8$ years; $\mathrm{P}<0.0001) .{ }^{30}$ This was corroborated by Zhang et $\mathrm{al}^{7}$ in a large-scale study which found that patients with diabetic retinopathy had a longer duration of diabetes $(15.0 \pm 1.6$ years vs $7.3 \pm 0.8$ years; $\mathrm{P}<0.001)$. Furthermore, Wong et $\mathrm{al}^{31}$ reported the OR of diabetic retinopathy increased by 1.07 \pm 0.2 per year of duration of disease. The LALES study found that each year of increased history of diabetes was associated with an $8 \%$ increased risk of having diabetic retinopathy. ${ }^{10}$ This association can be explained by a prolonged exposure to the hyperglycaemic state that may increase the risk of vascular injury, leading to diabetic retinopathy and other complications.

\section{Diabetic drug use}

Patients with diabetic retinopathy are also more likely to require medication such as oral hypoglycaemic agents or insulin to control their diabetes. In other words, known and treated diabetes is a predictor of diabetic retinopathy compared with unknown and untreated diabetes. ${ }^{32} \mathrm{~A}$ large-scale study performed in the Chinese population found that $90 \%$ of diabetic patients without retinopathy were either not on treatment, diet control, or oral hypoglycaemic agents. ${ }^{16}$ In contrast, almost $80 \%$ of patients with diabetic retinopathy required oral hypoglycaemic agents or insulin injections for diabetic control. ${ }^{16}$ Diabetic patients with diabetic retinopathy were statistically significantly more likely to use insulin $(47.4 \pm 8.3 \%$ vs $26.7 \pm 4.8 \%$; OR $=3.23) .{ }^{7}$ One study found the prevalence of diabetic retinopathy to be $70 \%$ in patients with type $2 \mathrm{DM}$ using insulin, compared with only $39 \%$ in those not receiving insulin treatment. ${ }^{33}$ These findings are consistent with several other studies. ${ }^{10,34}$ This relationship between insulin use and diabetic retinopathy may be explained by the severity and level of blood glucose control in patients. In other words, patients who did not require medication are likely those with borderline diabetes or relatively well controlled blood glucose profile, and thus have less risk of developing diabetic retinopathy.

The associations between diabetic risk factors and diabetic retinopathy are summarised in Table 1. ${ }^{6-8,16,21,24,29,30}$

\section{Systemic risk factors and diabetic retinopathy}

\section{Hypertension}

Hypertension has been consistently demonstrated to have a positive association with the development of diabetic retinopathy, ${ }^{4,6-8,30}$ The LALES study found an OR of $1.26(\mathrm{P}=0.002)$ for every $20 \mathrm{~mm} \mathrm{Hg}$ increase in blood pressure. ${ }^{10}$ The Hoorn study estimated that patients with hypertension had more than double the risk of developing retinopathy after 10 years when compared with diabetic patients with normal blood pressure. ${ }^{22}$ Stratton et $\mathrm{al}^{35}$ found that the incidence of developing new retinopathy increased from $17 \%$ to $32 \%$ when comparing the lowest tertile with the top third mean blood pressure in patients with diabetic retinopathy $(\mathrm{P}<0.0001)$. This gradient was less pronounced with $26 \%$ and $36 \%$ of progression in retinopathy when the bottom third was compared with the top tertile of blood pressure, respectively $(\mathrm{P}=0.005) .^{35}$ This marked association between hypertension and diabetic retinopathy may be explained by the clinical finding that hypertension and diabetes frequently co-exist. Hypertension may cause morphological changes in the retinal vessels that are similar to those seen in mild-to-moderate NPDR such as hard exudates, cotton-wool spots, and retinal haemorrhages. ${ }^{34}$

The landmark UKPDS 69 study has outlined the importance of blood pressure control in patients with diabetic retinopathy. ${ }^{21}$ The authors demonstrated that tight control of blood pressure with a target level of $150 / 85 \mathrm{~mm} \mathrm{Hg}$, rather than loose control of less than 180/105 mm Hg, statistically significantly decreased the development of microaneurysms (relative risk $[R R]=0.66$; $\mathrm{P}<0.001)$, hard exudates $(\mathrm{RR}=0.53 ; \mathrm{P}<0.001)$, and cotton-wool spots $(\mathrm{RR}=0.53 ; \quad \mathrm{P}<0.001)$. These effects were evident by 4.5 years of follow-up and persisted for up to 7.5 years. Furthermore, there were no detectable differences between blood pressure control by atenolol or captopril therapy, nor in primary or secondary prevention groups. Additionally, the loose blood pressure control group had an absolute risk of 4.1 per 1000 patient-years for blindness in one eye due to all causes $(\mathrm{P}=0.046$; $\mathrm{RR}=0.76$; 99\% CI, 0.29-1.99), in comparison with

TABLE I. Summary of diabetic risk factors and diabetic retinopathy ${ }^{6-8, \mid 6,21,24,29,30}$

\begin{tabular}{|c|c|c|c|}
\hline Risk factor & Modifiable or not & Association & Additional comments \\
\hline Glycaemic control & Modifiable & Positive & $\begin{array}{l}\mathrm{HbA1c} \text { level of } 7 \% \text { is ideal in reducing progression and new development of diabetic } \\
\text { retinopathy }{ }^{29}\end{array}$ \\
\hline Duration of diabetes & Unmodifiable & Positive & Prolonged duration of diabetes is a risk factor for diabetic retinopathy $6,8,16,21,24,30$ \\
\hline Diabetic drug use & Modifiable & Positive & Patients with diabetic retinopathy are more likely to require insulin for glycaemic control ${ }^{7}$ \\
\hline
\end{tabular}

Abbreviation: $\mathrm{HbAlc}=$ glycated haemoglobin 
an absolute risk of 3.1 per 1000 patient-years risk of blindness in the tight blood pressure control group..$^{21}$

The importance of tight blood pressure control could not be clearly demonstrated in both the Appropriate Blood Pressure Control in Diabetes (ABCD) Trial $^{36}$ or the ACCORD study. ${ }^{26}$ In the $A B C D$ Trial, subjects were randomised to intensive control group (diastolic blood pressure of $75 \mathrm{~mm} \mathrm{Hg}$ ) or moderate control group (diastolic blood pressure of $80-89 \mathrm{~mm} \mathrm{Hg}){ }^{36}$ The authors found no statistically significant difference in the progression of diabetic retinopathy over a 5-year follow-up period. Discrepancies in findings between the studies may be partially due to the difference in blood pressure targets. The authors of the ABCD Trial found that both groups had poor glycaemic control despite optimal blood pressure control and this may have accounted for the progression of diabetic retinopathy. ${ }^{36}$ This may further suggest the importance of glycaemic control in diabetic retinopathy. Likewise, the ACCORD study found no statistically significant relationship between intensive blood pressure therapy (median systolic blood pressure, $117 \mathrm{~mm} \mathrm{Hg}$ ) and standard therapy (median systolic blood pressure, $133 \mathrm{~mm} \mathrm{Hg}$ ) [10.4\% vs $8.8 \%$; adjusted $\mathrm{OR}=1.23$; $95 \% \mathrm{CI}, 0.84$ $1.79 ; \mathrm{P}=0.29] .{ }^{26}$ The authors hypothesised that these findings may be attributable to the small difference between blood pressure in the two groups.

\section{Obesity}

Obesity is another risk factor commonly associated with cardiovascular disease. It can be defined by waist-hip ratio, waist circumference, and body mass index (BMI). Both greater waist-hip ratio and waist circumference are positively associated with diabetic retinopathy. ${ }^{6,22,24}$ The OR of diabetic retinopathy is 1.28 per $5-\mathrm{cm}$ increase in waist circumference $(\mathrm{OR}=1.28$; 95\% CI, 1.05-1.56; $\mathrm{P}=0.014) .^{24}$

The association between BMI and diabetic retinopathy has been variable among studies. A study looking specifically at patients with type $1 \mathrm{DM}$ found that obesity with a BMI of $>30 \mathrm{~kg} / \mathrm{m}^{2}$ was the predominant risk factor for diabetic retinopathy, even when controlling for other risk factors such as $\mathrm{HbA} 1 \mathrm{c}$ and the use of cardioprotective drugs. ${ }^{37}$ In another study, obesity was associated with increased prevalence of retinopathy and patients with retinopathy were more likely to be obese, although this association was not sustained after adjusting for confounding factors such as blood pressure. ${ }^{30}$ Yet among patients with retinopathy, higher BMI was noted to be positively associated with more severe retinopathy and vision-threatening retinopathy. ${ }^{8}$

Some studies have reported no increased risk between elevated BMI and retinopathy. ${ }^{38,39}$ On the contrary, some studies have even reported an inverse relationship between BMI and diabetic retinopathy. The Wisconsin Epidemiologic Study of Diabetic Retinopathy found that underweight patients (BMI $<20 \mathrm{~kg} / \mathrm{m}^{2}$ ) with diabetes had a higher incidence of retinopathy compared with obese patients $(R R=1.99$; $95 \% \mathrm{CI}, 1.21-3.26$ vs $\mathrm{RR}=1.27$; $95 \% \mathrm{CI}, 1.00-1.61) .{ }^{40} \mathrm{In}$ fact, $100 \%$ of the underweight patients in this study developed retinopathy by 10 years. This observation held true for the progression of retinopathy as well. The authors observed that the underweight patients had a longer duration of diabetes and were also more likely to be taking insulin than the obese subjects. Thus, they hypothesised that the underweight patients might have had poorer overall glycaemic control and hence were in a more 'severe' phase of diabetes when compared with their obese counterparts. ${ }^{40}$ This hypothesis also corroborates the findings of the DCCT study that tight glycaemic control increases the risk of being overweight. ${ }^{28}$ Although not statistically significant, Wong et $\mathrm{al}^{31}$ reported that a lower BMI was associated with diabetic retinopathy.

\section{$\operatorname{Sex}$}

Male sex is an independent risk factor for diabetic retinopathy. A large-scale study performed in the United States revealed that in diabetic patients over the age of 40 years, $38 \% \pm 5.5 \%$ of men compared with $27.1 \% \pm 4.7 \%$ of women had diabetic retinopathy $\left(\mathrm{OR}=2.07\right.$; 95\% CI, 1.39-3.10). ${ }^{7}$ While the LALES study showed no statistically significant difference in the incidence of diabetic retinopathy between different sexes, their stepwise multivariate model demonstrated that men had a $50 \%$ higher risk of having any diabetic retinopathy when compared with females $(\mathrm{OR}=1.50 ; \mathrm{P}=0.006) .{ }^{10}$ This finding was echoed by the UKPDS 50 study that also found no difference in incidence between the two sexes $(\mathrm{P}=0.67)$, but a multivariate model showed that women had a lower RR of progression of diabetic retinopathy $(\mathrm{RR}=0.54 ; \mathrm{CI}, 0.37-0.80 ; \mathrm{P}=0.0016) .{ }^{35}$ Despite the above evidence, several other studies have found no statistically significant associations between diabetic retinopathy and sex..$^{22,30}$

\section{Hyperlipidaemia}

Studies have found varying relationships between elevated cholesterol and diabetic retinopathy. While Yau et $\mathrm{al}^{5}$ reported that elevated total serum cholesterol was associated with a higher prevalence of diabetic macular oedema and vision-threatening diabetic retinopathy, other studies have been unable to reproduce similar results. Tomić et $\mathrm{al}^{34}$ demonstrated no statistically significant difference in cholesterol level between patients with different severity of diabetic retinopathy. The Hoorn study also found no relationship between total cholesterol level and incidence of diabetic retinopathy, ${ }^{22}$ but 
demonstrated that elevated serum lipid level is associated with increased prevalence of hard exudates characterising NPDR. ${ }^{41}$ This association of elevated serum lipid levels and hard exudates was observed in other studies as well. ${ }^{42-44}$ Patients with type $1 \mathrm{DM}$ with diabetic retinopathy have been shown to have statistically significantly higher total cholesterol level than those without diabetic retinopathy $(199 \pm 35 \mathrm{mg} / \mathrm{dL}$ vs $188 \pm 36 \mathrm{mg} / \mathrm{dL}$; $\mathrm{P}=0.001$ ), although after logistic regression analysis this was not shown to be an independent risk factor for diabetic retinopathy. ${ }^{30}$ On the contrary, Wong et $\mathrm{al}^{31}$ reported higher total cholesterol level to be protective of diabetic retinopathy $(\mathrm{OR}=0.73$, per 1 $\mathrm{mmol} / \mathrm{L}$ increase).

Studies showed inconsistent results in the relationship between serum triglycerides and diabetic retinopathy. The Hoorn study, ${ }^{22}$ De Block et al, ${ }^{30}$ and Tomić et $\mathrm{al}^{34}$ have all demonstrated that serum triglyceride levels are not an independent risk factor for diabetic retinopathy. Likewise, in a large-scale study of 2535 patients with type 2 DM, retinopathy was not significantly associated with triglyceride or high-density lipoprotein (HDL) cholesterol levels after adjustment of confounding factors. ${ }^{45}$ In contrast, Cheng at $\mathrm{al}^{4}$ found that in overweight type 2 DM patients, elevated triacylglycerol levels were significantly associated with diabetic retinopathy $(\mathrm{OR}=1.29 ; 95 \% \mathrm{CI}, 1.05-1.58 ; \mathrm{P}<0.05)$.

Despite the conflicting data, there appears to be merit in treating hyperlipidaemia in patients with diabetic retinopathy. The ACCORD trial investigated the effects of intensive treatment of dyslipidaemia on the progression of diabetic retinopathy. ${ }^{26}$ Patients in the intensive treatment group were given $160 \mathrm{mg}$ of fenofibrate daily plus simvastatin, while patients in the standard treatment group were given placebo with simvastatin. The authors found a significant improvement in HDL cholesterol $(\mathrm{P}=0.002)$ and significant decrease in triglyceride level $(\mathrm{P}<0.001)$ in the intensive treatment group. As expected, fall in low-density lipoprotein cholesterol level was comparable between the two groups $(\mathrm{P}=0.68)$ as both received simvastatin. With the significant improvement in lipid profile, the authors found that intensive therapy decreased the risk of progression of diabetic retinopathy compared with simvastatin alone, $6.5 \%$ vs $10.2 \%$ (adjusted $\mathrm{OR}=0.60 ; 95 \% \mathrm{CI}$, 0.42-0.87; $\mathrm{P}=0.006) .{ }^{26} \mathrm{~A}$ more recent meta-analysis by $D$ as et $\mathrm{al}^{46}$ found no statistically significant improvement in severity of diabetic macular oedema or decrease in progression of hard exudates in patients receiving lipid-lowering drugs compared with placebo. The authors, however, remarked that studies included in the meta-analysis were of questionable quality, calling to the necessity for further high-quality research. Studies included in the meta-analysis by Das et $\mathrm{al}^{46}$ had small sample sizes, underpowered studies, and poor subject selection criteria since patients included had earlystage diabetic retinopathy and hence were at low risk of progression.

\section{Chronic kidney disease}

Both retinopathy and nephropathy are microvascular complications of diabetic retinopathy. Multiple studies have demonstrated the association between diabetic retinopathy and chronic kidney disease. In a study by Park et $\mathrm{al}^{47}$ in a Korean population, the authors defined chronic kidney disease as estimated glomerular filtration rate (eGFR) of $<60 \mathrm{~mL} / \mathrm{min} / 1.73 \mathrm{~m}^{3}$. They reported that even after controlling for confounders, both chronic kidney disease $(\mathrm{OR}=2.34 ; 95 \% \mathrm{CI}, 1.04-5.28)$ and proteinuria $(\mathrm{OR}=4.56$; 95\% CI, 1.51-13.77) were significantly associated with diabetic retinopathy. ${ }^{47}$ Additionally, Zhang et $\mathrm{al}^{48}$ found that in the Chinese population, lower eGFR was significantly associated with increasing severity of diabetic retinopathy in patients with diabetic retinopathy (mean eGFR, 93 $\mathrm{mL} / \mathrm{min} / 1.73 \mathrm{~m}^{3}$ ) compared with patients without (mean eGFR, $116 \mathrm{~mL} / \mathrm{min} / 1.73 \mathrm{~m}^{3} ; \mathrm{P}<0.0001$ ), independent of hypertension and diabetes duration. Diabetic retinopathy was also associated with microalbuminuria $(\mathrm{P}<0.0001)$ and higher albuminto-creatinine ratio (6.4 vs 0.63 in patients with and without diabetic retinopathy, respectively). The authors suggested that in diabetic patients, chronic hyperglycaemia causes microvascular changes in both the glomerulus of the kidney and retina of the eye. Over time, these microvascular changes lead to narrowing and occlusion of the vascular lumina, and eventually cause inadequate perfusion of affected tissues leading to retinopathy and nephropathy. ${ }^{48}$ These findings were corroborated by Penno et $\mathrm{al}^{49}$ who reported that a high urine albumin-to-creatinine ratio of $\geq 300 \mathrm{mg} / \mathrm{g}$ was associated with diabetic retinopathy $(\mathrm{OR}=2.9 ; 95 \%$ CI, 2.1-4.0). Likewise, Rodríguez-Poncelas et $\mathrm{al}^{50}$ found that increasing urine albumin-to-creatinine ratio was significantly correlated with rising diabetic retinopathy prevalence, and this association was significant even at urine albumin-to-creatinine levels of $\geq 10 \mathrm{mg} / \mathrm{g}(\mathrm{OR}=1.2 ; 95 \% \mathrm{CI}, 1.1-1.4)$.

\section{Smoking}

Smoking was shown to have neither a statistically significantly positive nor negative association with diabetic retinopathy. The Hoorn study demonstrated a non-significant trend for increased OR of diabetic retinopathy incidence in cigarette smokers and exsmokers. ${ }^{22}$ A 25-year follow-up study showed a nonsignificant trend that current smokers were more likely to develop proliferative diabetic retinopathy than never smokers, yet was unable to establish a statistically significant association between smoking 
status or pack-years of smoking and proliferative diabetic retinopathy. The authors found that mild NPDR was more common among current smokers than former smokers $(28.4 \%$ vs $13.0 \%$; $\mathrm{P}=0.038)$ and may suggest that smoking is indeed related to early forms of diabetic retinopathy. ${ }^{51}$ On the contrary, the UKPDS 50 study demonstrated a protective effect of smoking-current smokers had a reduced incidence of retinopathy with a RR of 0.63 (95\% CI, 0.4-0.82; $\mathrm{P}=0.0043)$ as well as reduced progression of retinopathy with a RR of 0.50 (95\% CI, 0.36-0.71, $\mathrm{P}=0.0045)$ when compared with never smokers. ${ }^{35}$

\section{Myopia}

Long-sightedness is prevalent among Asians and it has become a significant problem in this locality in terms of resources for glasses prescriptions, refractive surgeries, and the management of visualthreatening complications such as myopic macular degeneration, myopic tractional maculopathy, and choroidal neovascularisation. Although myopia in most cases is harmful to ocular health, it has long been observed that the prevalence of diabetic retinopathy is low in myopic patients. This protective effect of myopia against diabetic retinopathy has recently been proven by various meta-analysis, ${ }^{52,53}$ revealing the OR of diabetic retinopathy in myopic diabetic patients versus non-myopic diabetic patients to be 0.70 (95\% CI, 0.58-0.85; $\mathrm{P}<0.001)$. On the contrary, axial length, the major cause of myopia, was found to be associated with diabetic retinopathy as well, in which each millimetre increase in axial length is associated with decreased risk of diabetic retinopathy $(\mathrm{OR}=0.75 ; 95 \% \mathrm{CI}, 0.65-0.86$; $\mathrm{P}<0.001)$.

The relationships between systemic risk factors and diabetic retinopathy are summarised in Table 2. ${ }^{4-8,10,19,21,22,24,28,30,34,38-40,42-44,47-53}$

\section{Genetic polymorphisms and diabetic retinopathy}

While genetic polymorphism is not a modifiable risk factor, various genetic polymorphisms may cause a predisposition to the development and progression of diabetic retinopathy. Multiple studies have demonstrated the relationship between TCF7L 2 and the development of type 2 diabetes $^{54-56}$ as increased expression of this gene is associated with poor serum glucose control. Ciccacci et $\mathrm{al}^{57}$ found that patients with rs12255372 or rs7903146 variants of TCF7L2 were at higher risk of developing diabetic retinopathy. Within the Chinese population, patients with rs6585205, rs7903146, and rs11196218 had a weakly positive but not statistically significant association with development of diabetic retinopathy. ${ }^{58} \mathrm{~A}$ meta-analysis conducted by Ding et $\mathrm{al}^{59}$ found that the rs7903146 variant ( $\mathrm{T}$ allele) of TCF7L2 was significantly associated with increased risk of development of diabetic retinopathy $(\mathrm{OR}=1.47 ; 95 \%$ CI, 1.19-1.81; $\mathrm{P} \leq 0.001$ for TT vs $C C$ when comparing genotype polymorphism TT, TC, and CC) especially within the Caucasian population. Due to rarity of the $\mathrm{T}$ allele within East Asian populations (estimated at $4.47 \%^{60}$ and $6.997 \% 58$ in two different studies), however, this may be not applicable to this locality.

A meta-analysis by Ma et $\mathrm{ll}^{61}$ reported a positive association between Pro12Ala polymorphism of the peroxisome proliferator-activated receptor $\gamma 2$ (PPAR 2$)$ gene. The PPAR 2 gene plays a key role in multiple pathways including glucose metabolism, angiogenesis, and inflammation. The authors found that the Ala allele yielded a protective effect against diabetic retinopathy in patients with type $2 \mathrm{DM}(\mathrm{OR}=0.81 ; 95 \% \mathrm{CI}, 0.68-0.98 ; \mathrm{P}=0.03)$. This association was stronger in Caucasian subgroups

TABLE 2. Summary of systemic risk factors and diabetic retinopathy $4-8,10,21,22,24,28,30,34,38-40,42-44,47-53$

\begin{tabular}{|c|c|c|c|}
\hline Risk factor & Modifiable or not & Association & Additional comments \\
\hline Hypertension & Modifiable & Positive & $\begin{array}{l}\text { Hypertension has a positive association with the development of diabetic } \\
\text { retinopathy } y^{4,6-8,30}\end{array}$ \\
\hline Obesity & Modifiable & $\begin{array}{l}\text { Positive for waist-hip ratio } \\
\text { and waist circumference } \\
\text { Indeterminate for BMI }\end{array}$ & $\begin{array}{l}\text { Greater waist-hip ratio and waist circumference are positively associated with } \\
\text { diabetic retinopathy } \\
\text { Studies have shown no increased risk or an inverse relationship }{ }^{38,39} \text { between BMl } \\
\text { and diabetic retinopathy }{ }^{28,40}\end{array}$ \\
\hline Sex & Unmodifiable & Indeterminate & $\begin{array}{l}\text { While some studies have demonstrated male sex as an independent risk factor } \\
\text { for diabetic retinopathy, }{ }^{7,10,21} \text { other studies fail to replicate this relationship }{ }^{22,30}\end{array}$ \\
\hline Hyperlipidaemia & Modifiable & Indeterminate & $\begin{array}{l}\text { Some studies demonstrated a positive relationship, }, 52-44 \text { while others showed no } \\
\text { relationship }{ }^{22,30,34} \text { between diabetic retinopathy and hyperlipidaemia }\end{array}$ \\
\hline $\begin{array}{l}\text { Chronic kidney } \\
\text { disease }\end{array}$ & Unmodifiable & Positive & $\begin{array}{l}\text { Diabetic retinopathy is positively associated with chronic kidney disease }{ }^{47,48} \text { and } \\
\text { high urine albumin-to-creatinine ratio }{ }^{48-50}\end{array}$ \\
\hline Smoking & Modifiable & Indeterminate & $\begin{array}{l}\text { Several studies have shown a non-significant positive trend between diabetic } \\
\text { retinopathy and smoking, }{ }^{22,51} \text { but the UKPDS } 50 \text { has demonstrated a protective } \\
\text { effect of smoking }{ }^{21}\end{array}$ \\
\hline Myopia & Unmodifiable & Negative & Myopia has a protective effect against diabetic retinopathy ${ }^{52,53}$ \\
\hline
\end{tabular}

Abbreviations: $\mathrm{BMI}=$ body mass index; UKPDS = United Kingdom Prospective Diabetes Study 
compared with Asian subgroups, possibly due to differences in allele frequencies and study design. ${ }^{61}$

A recent study by Peng et $\mathrm{al}^{62}$ demonstrated that the C-reactive protein (CRP) variant rs2808629 is statistically significantly associated with increased risk of diabetic retinopathy $(\mathrm{OR}=1.296 ; 95 \% \mathrm{CI}$, 1.076-1.561; $\mathrm{P}=0.006$ for $\mathrm{G}$ allele) in Chinese patients with type 2 DM. Even after adjusting for confounding factors associated with diabetic retinopathy, this variant of CRP remained an independent genetic risk factor for development of diabetic retinopathy.$^{62}$ Patients with rs2808629 have been demonstrated to have higher levels of serum CRP. ${ }^{63}$ Yet, there have been no conclusive findings of the relationship between high CRP levels and the development of diabetic retinopathy as studies have demonstrated contradicting results. ${ }^{64-68}$ The exact mechanism of how rs2808629 causes increased risk of diabetic retinopathy warrants further research.

Another comprehensive study by Peng et $\mathrm{al}^{69}$ sought to establish the relationship between 40 single nucleotide polymorphisms and diabetic retinopathy in Chinese patients with type 2DM. The authors found that $\mathrm{rs} 17684886$ in $Z N R F 1 \quad(\mathrm{OR}=0.812 ; \mathrm{P}=0.0039)$ and rs599019 near COLEC12 (OR=0.835; $\mathrm{P}=0.0116)$ were associated with an increased risk of diabetic retinopathy. rs6427247 near SCYL1BP1 (OR $=1.368$; $\mathrm{P}=0.0333)$ and $\mathrm{rs} 899036$ near API5 (OR $=0.340$; $\mathrm{P}=0.0005)$ were associated with increased risk of severe diabetic retinopathy. ${ }^{69}$ This is consistent with other genome-wide association studies in Caucasian and Mexican-American patients..$^{70,71}$

As the relationship between genetic polymorphisms and diabetic retinopathy is still a new and emerging field, some studies have demonstrated new associations between single nucleotide polymorphisms, but these studies have not yet been replicable. Further studies are thus warranted.
Diabetic retinopathy and its genetic risk factors are listed in Table 3. ${ }^{57,58,60-63}$

\section{Conclusions}

The importance of glycaemic control and duration of diabetes with diabetic retinopathy have been clearly established. Additionally, the modality of diabetic treatment may reflect the severity of diabetes and risk of developing diabetic retinopathy. Patients with DM should be encouraged to optimise their control of the disease in order to prevent the development and progression of diabetic retinopathy. Of the systemic risk factors studied, multiple studies clearly establish a positive association between hypertension and diabetic retinopathy. Studies have shown varying results for the association of diabetic retinopathy with obesity, male sex, hyperlipidaemia, and smoking. Additionally, declining renal function and microalbuminuria have been demonstrated to be associated with increased prevalence of diabetic retinopathy. In contrast, myopia is protective against development of diabetic retinopathy. Despite inconsistent findings for the association of systemic risk factors with diabetic retinopathy, it is still important for clinicians to encourage patients to optimise their body weight, lipid profile, and to abstain from smoking due to their associations with risk for cardiovascular disease as well as other complications of diabetes. New research has also demonstrated an increasing number of genetic polymorphisms associated with risk of type 2 DM and the development of diabetic retinopathy. Investigating the polymorphisms associated with diabetic retinopathy may help us better understand the developmental pathway of diabetic retinopathy and lead to new targeted therapy in treating diabetes and preventing diabetic retinopathy.

TABLE 3. Summary of genetic polymorphisms and diabetic retinopathy ${ }^{57,58,60-62,69-71}$

\begin{tabular}{|c|c|c|c|}
\hline & Modifiable or not & Association & Additional comments \\
\hline TCF7L2 & Unmodifiable & Positive & $\begin{array}{l}\text { rs } 12255372 \text { or rs } 7903146 \text { positively associated with diabetic retinopathy. }{ }^{57,60} \text { rs } 6585205 \\
\text { rs } 7903146 \text { and rs } 11196218 \text { had a weakly positive but not statistically significant } \\
\text { association in Chinese population }\end{array}$ \\
\hline Pro12Ala & Unmodifiable & Negative & $\begin{array}{l}\text { Ala allele yielded a protective effect against diabetic retinopathy especially in } \\
\text { Caucasians } \\
61\end{array}$ \\
\hline CRP rs2808629 & Unmodifiable & Positive & rs2808629 positively associated with increased risk of diabetic retinopathy in Chinese ${ }^{62}$ \\
\hline rs17684886 in ZNRF1 & Unmodifiable & Positive & rs17684886 in ZNRF1 positively associated with increased risk of diabetic retinopathy ${ }^{69-71}$ \\
\hline $\begin{array}{l}\text { rs599019 near } \\
\text { COLEC12 }\end{array}$ & Unmodifiable & Positive & $\begin{array}{l}\text { rs599019 near COLEC12 positively associated with increased risk of diabetic } \\
\text { retinopathy }{ }^{69-71}\end{array}$ \\
\hline $\begin{array}{l}\text { rs6427247 near } \\
\text { SCYL1BP1 }\end{array}$ & Unmodifiable & Positive & $\begin{array}{l}\text { rs6427247 near SCYL1BP1 positively associated with increased risk of severe diabetic } \\
\text { retinopathy }{ }^{69-71}\end{array}$ \\
\hline rs899036 near API5 & Unmodifiable & Positive & $\begin{array}{l}\text { rs899036 near API5 positively associated with increased risk of severe diabetic } \\
\text { retinopathy }\end{array}$ \\
\hline
\end{tabular}




\section{Declaration}

All authors have disclosed no conflicts of interest.

\section{References}

1. Cheung N, Mitchell P, Wong TY. Diabetic retinopathy. Lancet 2010;376:124-36.

2. Klein R, Klein BE, Moss SE, Cruickshanks KJ. The Wisconsin Epidemiologic Study of Diabetic Retinopathy: XVII. The 14-year incidence and progression of diabetic retinopathy and associated risk factors in type 1 diabetes. Ophthalmology 1998;105:1801-15.

3. Kannel WB, McGee DL. Diabetes and cardiovascular risk factors: the Framingham study. Circulation 1979;59:8-13.

4. Cheng $\mathrm{Y}$, Zhang $\mathrm{H}$, Chen $\mathrm{R}$, et al. Cardiometabolic risk profiles associated with chronic complications in overweight and obese type 2 diabetes patients in South China. PLoS One 2014;9:e101289.

5. Yau JW, Rogers SL, Kawasaki R, et al. Global prevalence and major risk factors of diabetic retinopathy. Diabetes Care 2012;35:556-64.

6. Wong TY, Klein R, Islam FM, et al. Diabetic retinopathy in a multi-ethnic cohort in the United States. Am J Ophthalmol 2006;141:446-55.

7. Zhang X, Saaddine JB, Chou CF, et al. Prevalence of diabetic retinopathy in the United States, 2005-2008. JAMA 2010;304:649-56.

8. Raum P, Lamparter J, Ponto KA, et al. Prevalence and cardiovascular associations of diabetic retinopathy and maculopathy: results from the Gutenberg Health Study. PLoS One 2015;10:e0127188.

9. Bertelsen G, Peto T, Lindekleiv $H$, et al. Sex differences in risk factors for retinopathy in non-diabetic men and women: the Tromsø Eye Study. Acta Ophthalmol 2014;92:316-22.

10. Varma R, Macias GL, Torres M, et al. Biologic risk factors associated with diabetic retinopathy: the Los Angeles Latino Eye Study. Ophthalmology 2007;114:1332-40.

11. Tam TK, Lau CM, Tsang LC, Ng KK, Ho KS, Lai TC. Epidemiological study of diabetic retinopathy in a primary care setting in Hong Kong. Hong Kong Med J 2005;11:43844.

12. Tam VH, Lam EP, Chu BC, Tse KK, Fung LM. Incidence and progression of diabetic retinopathy in Hong Kong Chinese with type 2 diabetes mellitus. J Diabetes Complications 2009;23:185-93.

13. Wang WQ, Ip TP, Lam KS. Changing prevalence of retinopathy in newly diagnosed non-insulin dependent diabetes mellitus patients in Hong Kong. Diabetes Res Clin Pract 1998;39:185-91.

14. Lian JX, Gangwani RA, McGhee SM, et al. Systematic screening for diabetic retinopathy (DR) in Hong Kong: prevalence of DR and visual impairment among diabetic population. Br J Ophthalmol 2016;100:151-5.

15. Chen MS, Kao CS, Chang CJ, et al. Prevalence and risk factors of diabetic retinopathy among noninsulindependent diabetic subjects. Am J Ophthalmol 1992;114:723-30.

16. Xie XW, Xu L, Wang YX, Jonas JB. Prevalence and associated factors of diabetic retinopathy. The Beijing Eye Study 2006. Graefes Arch Clin Exp Ophthalmol 2008;246:1519-26.

17. Wang FH, Liang YB, Zhang F, et al. Prevalence of diabetic retinopathy in rural China: the Handan Eye Study. Ophthalmology 2009;116:461-7.

18. Ramachandran A, Snehalatha C, Vijay V, King H. Impact of poverty on the prevalence of diabetes and its complications in urban southern India. Diabet Med 2002;19:130-5.

19. Grading diabetic retinopathy from stereoscopic color fundus photographs-an extension of the modified Airlie House classification. ETDRS report number 10. Early Treatment Diabetic Retinopathy Study Research Group. Ophthalmology 1991;98(5 Suppl):786S-806S

20. Core NDESP team. Diabetic eye screening feature based grading forms. NHS Diabetic Eye Screening Programme; 2012.

21. Matthews DR, Stratton IM, Aldington SJ, Holman RR, Kohner EM, UK Prospective Diabetes Study Group. Risks of progression of retinopathy and vision loss related to tight blood pressure control in type 2 diabetes mellitus: UKPDS 69. Arch Ophthalmol 2004;122:1631-40.

22. van Leiden HA, Dekker JM, Moll AC, et al. Risk factors for incident retinopathy in a diabetic and nondiabetic population: the Hoorn study. Arch Ophthalmol 2003;121:245-51.

23. Intensive blood-glucose control with sulphonylureas or insulin compared with conventional treatment and risk of complications in patients with type 2 diabetes (UKPDS 33). UK Prospective Diabetes Study (UKPDS) Group. Lancet 1998;352:837-53.

24. Rajalakshmi R, Amutha A, Ranjani H, et al. Prevalence and risk factors for diabetic retinopathy in Asian Indians with young onset type 1 and type 2 diabetes. J Diabetes Complications 2014;28:291-7.

25. Zhang L, Chen B, Tang L. Metabolic memory: mechanisms and implications for diabetic retinopathy. Diabetes Res Clin Pract 2012;96:286-93.

26. ACCORD Study Group, ACCORD Eye Study Group, Chew EY, et al. Effects of medical therapies on retinopathy progression in type 2 diabetes. N Engl J Med 2010;363:23344.

27. Action to Control Cardiovascular Risk in Diabetes Study Group, Gerstein HC, Miller ME, et al. Effects of intensive glucose lowering in type 2 diabetes. $N$ Engl J Med 2008;358:2545-59.

28. The effect of intensive treatment of diabetes on the development and progression of long-term complications in insulin-dependent diabetes mellitus. The Diabetes Control and Complications Trial Research Group. N Engl J Med 1993;329:977-86.

29. Mohamed Q, Gillies MC, Wong TY. Management of diabetic retinopathy: a systematic review. JAMA 2007;298:902-16.

30. De Block CE, De Leeuw IH, Van Gaal LF. Impact of overweight on chronic microvascular complications in type 1 diabetic patients. Diabetes Care 2005;28:1649-55.

31. Wong TY, Cheung N, Tay WT, et al. Prevalence and risk factors for diabetic retinopathy: the Singapore Malay Eye Study. Ophthalmology 2008;115:1869-75.

32. Lim MC, Lee SY, Cheng BC, et al. Diabetic retinopathy in diabetics referred to a tertiary centre from a nationwide screening programme. Ann Acad Med Singapore 2008;37:753-9.

33. Klein R, Klein BE, Moss SE, Davis MD, DeMets DL. The Wisconsin epidemiologic study of diabetic retinopathy. III. Prevalence and risk of diabetic retinopathy when 
age at diagnosis is 30 or more years. Arch Ophthalmol 1984;102:527-32.

34. Tomić M, Ljubić S, Kaštelan S, Gverović Antunica A, Jazbec A, Poljičanin T. Inflammation, haemostatic disturbance, and obesity: possible link to pathogenesis of diabetic retinopathy in type 2 diabetes. Mediators Inflamm 2013;2013:818671.

35. Stratton IM, Kohner EM, Aldington SJ, et al. UKPDS 50: risk factors for incidence and progression of retinopathy in type II diabetes over 6 years from diagnosis. Diabetologia 2001;44:156-63.

36. Estacio RO, Jeffers BW, Gifford N, Schrier RW. Effect of blood pressure control on diabetic microvascular complications in patients with hypertension and type 2 diabetes. Diabetes Care 2000;23 Suppl 2:B54-64.

37. Price SA, Gorelik A, Fourlanos S, Colman PG, Wentworth JM. Obesity is associated with retinopathy and macrovascular disease in type 1 diabetes. Obes Res Clin Pract 2014;8:e178-82.

38. Nelson RG, Wolfe JA, Horton MB, Pettitt DJ, Bennett $\mathrm{PH}$, Knowler WC. Proliferative retinopathy in NIDDM Incidence and risk factors in Pima Indians. Diabetes 1989;38:435-40.

39. Lee ET, Lee VS, Lu M, Russell D. Development of proliferative retinopathy in NIDDM. A follow-up study of American Indians in Oklahoma. Diabetes 1992;41:359-67.

40. Klein R, Klein BE, Moss SE. Is obesity related to microvascular and macrovascular complications in diabetes? The Wisconsin Epidemiologic Study of Diabetic Retinopathy. Arch Intern Med 1997;157:650-6.

41. van Leiden HA, Dekker JM, Moll AC, et al. Blood pressure, lipids, and obesity are associated with retinopathy: the Hoorn study. Diabetes Care 2002;25:1320-5.

42. Klein BE, Moss SE, Klein R, Surawicz TS. The Wisconsin Epidemiologic Study of Diabetic Retinopathy. XIII. Relationship of serum cholesterol to retinopathy and hard exudate. Ophthalmology 1991;98:1261-5.

43. Chew EY, Klein ML, Ferris FL 3rd, et al. Association of elevated serum lipid levels with retinal hard exudate in diabetic retinopathy. Early Treatment Diabetic Retinopathy Study (ETDRS) Report 22. Arch Ophthalmol 1996;114:1079-84.

44. Chaturvedi N, Sjoelie AK, Porta M, et al. Markers of insulin resistance are strong risk factors for retinopathy incidence in type 1 diabetes. Diabetes Care 2001;24:284-9.

45. Sacks FM, Hermans MP, Fioretto P, et al. Association between plasma triglycerides and high-density lipoprotein cholesterol and microvascular kidney disease and retinopathy in type 2 diabetes mellitus: a global casecontrol study in 13 countries. Circulation 2014;129:9991008.

46. Das R, Kerr R, Chakravarthy U, Hogg RE. Dyslipidemia and diabetic macular edema: a systematic review and meta-analysis. Ophthalmology 2015;122:1820-7.

47. Park YH, Shin JA, Han JH, Park YM, Yim HW. The association between chronic kidney disease and diabetic retinopathy: the Korea national health and nutrition examination survey 2008-2010. PLoS One 2015;10:e0125338.

48. Zhang H, Wang J, Ying GS, Shen L, Zhang Z. Diabetic retinopathy and renal function in Chinese type 2 diabetic patients. Int Urol Nephrol 2014;46:1375-81.

49. Penno G, Solini A, Zoppini G, et al. Rate and determinants of association between advanced retinopathy and chronic kidney disease in patients with type 2 diabetes: the Renal Insufficiency And Cardiovascular Events (RIACE) Italian multicenter study. Diabetes Care 2012;35:2317-23.

50. Rodríguez-Poncelas A, Mundet-Tudurí X, Miravet-Jiménez $\mathrm{S}$, et al. Chronic kidney disease and diabetic retinopathy in patients with type 2 diabetes. PLoS One 2016;11:e0149448.

51. Gaedt Thorlund M, Borg Madsen M, Green A, Sjølie AK, Grauslund J. Is smoking a risk factor for proliferative diabetic retinopathy in type 1 diabetes? Ophthalmologica 2013;230:50-4.

52. Fu Y, Geng D, Liu H, Che H. Myopia and/or longer axial length are protective against diabetic retinopathy: a metaanalysis. Acta Ophthalmol 2016;94:346-52.

53. Wang X, Tang L, Gao L, Yang Y, Cao D, Li Y. Myopia and diabetic retinopathy: a systematic review and metaanalysis. Diabetes Res Clin Pract 2016;111:1-9.

54. Grant RW, Moore AF, Florez JC. Genetic architecture of type 2 diabetes: recent progress and clinical implications. Diabetes Care 2009;32:1107-14.

55. Grant SF, Thorleifsson G, Reynisdottir I, et al. Variant of transcription factor 7-like 2 (TCF7L2) gene confers risk of type 2 diabetes. Nat Genet 2006;38:320-3.

56. Cauchi S, Froguel P. TCF7L2 genetic defect and type 2 diabetes. Curr Diab Rep 2008;8:149-55.

57. Ciccacci C, Di Fusco D, Cacciotti L, et al. TCF7L2 gene polymorphisms and type 2 diabetes: association with diabetic retinopathy and cardiovascular autonomic neuropathy. Acta Diabetol 2013;50:789-99.

58. Fu LL, Lin Y, Yang ZL, Yin YB. Association analysis of genetic polymorphisms of TCF7L2, CDKAL1, SLC30A8, HHEX genes and microvascular complications of type 2 diabetes mellitus [in Chinese]. Zhonghua Yi Xue Yi Chuan Xue Za Zhi 2012;29:194-9.

59. Ding Y, Hu Z, Yuan S, Xie P, Liu Q. Association between transcription factor 7-like 2 rs7903146 polymorphism and diabetic retinopathy in type 2 diabetes mellitus: A metaanalysis. Diab Vasc Dis Res 2015;12:436-44.

60. Choi HJ, Lee DH, Jeon HJ, Kim DS, Lee YH, Oh T Transcription factor 7-like 2 (TCF7L2) gene polymorphism rs7903146 is associated with stroke in type 2 diabetes patients with long disease duration. Diabetes Res Clin Pract 2014;103:e3-6.

61. Ma J, Li Y, Zhou F, Xu X, Guo G, Qu Y. Meta-analysis of association between the Pro12Ala polymorphism of the peroxisome proliferator-activated receptor-gamma2 gene and diabetic retinopathy in Caucasians and Asians. Mol Vis 2012;18:2352-60.

62. Peng D, Wang J, Zhang R, et al. C-reactive protein genetic variant is associated with diabetic retinopathy in Chinese patients with type 2 diabetes. BMC Endocr Disord 2015;15:8

63. Benjamin EJ, Dupuis J, Larson MG, et al. Genome-wide association with select biomarker traits in the Framingham Heart Study. BMC Med Genet 2007;8 Suppl 1:11S.

64. Klein BE, Knudtson MD, Tsai MY, Klein R. The relation of markers of inflammation and endothelial dysfunction to the prevalence and progression of diabetic retinopathy: Wisconsin epidemiologic study of diabetic retinopathy. Arch Ophthalmol 2009;127:1175-82.

65. Lim LS, Tai ES, Mitchell P, et al. C-reactive protein, body mass index, and diabetic retinopathy. Invest Ophthalmol Vis Sci 2010;51:4458-63. 
66. Muni RH, Kohly RP, Lee EQ, Manson JE, Semba RD, Schaumberg DA. Prospective study of inflammatory biomarkers and risk of diabetic retinopathy in the diabetes control and complications trial. JAMA Ophthalmol 2013;131:514-21.

67. Nguyen TT, Alibrahim E, Islam FM, et al. Inflammatory, hemostatic, and other novel biomarkers for diabetic retinopathy: the multi-ethnic study of atherosclerosis. Diabetes Care 2009;32:1704-9.

68. van Hecke MV, Dekker JM, Nijpels G, et al. Inflammation and endothelial dysfunction are associated with retinopathy: the Hoorn Study. Diabetologia 2005;48:1300-
6.

69. Peng D, Wang J, Zhang R, et al. Common variants in or near ZNRF1, COLEC12, SCYL1BP1 and API5 are associated with diabetic retinopathy in Chinese patients with type 2 diabetes. Diabetologia 2015;58:1231-8.

70. Fu YP, Hallman DM, Gonzalez VH, et al. Identification of diabetic retinopathy genes through a genome-wide association study among Mexican-Americans from Starr County, Texas. J Ophthalmol 2010;2010.pii: 861291.

71. Grassi MA, Tikhomirov A, Ramalingam S, Below JE, Cox NJ, Nicolae DL. Genome-wide meta-analysis for severe diabetic retinopathy. Hum Mol Genet 2011;20:2472-81. 